\title{
A EQUILIBRAÇÃO MAJORANTE EM CRIANÇAS DE EDUCAÇÃO INFANTIL: UM ESTUDO DE CASO
}

\author{
Adriano Canabarro Teixeira (UPF)* \\ Caroline da Silva Furini (UPF)** \\ Flávia Eloisa Caimi (UPF)***
}

\begin{abstract}
RESUMO
A programação de computadores é uma competência técnica com potencial para o desenvolvimento cognitivo humano. Nesse sentido, é fundamental que seja explorada sua aplicabilidade no contexto da educação infantil, tema raro na produção científica na área de Educação. Assim, o estudo objetivou identificar a relação entre o conceito de equilibração majorante de Piaget com as atividades de programação de computadores realizadas por crianças da educação infantil participantes do Projeto Berçário de Hackers. Os procedimentos metodológicos utilizados constituíram-se de pesquisa qualitativa, com abordagem de pesquisa-ação, envolvendo observação participante nas oficinas e videogravações. O trabalho de campo foi desenvolvido com 19 crianças de cinco e seis anos, sendo selecionados dois estudantes para uma análise mais detida. Os resultados apontam para a presença de indícios de equilibração majorante, manifestada em regulações ativas e automáticas.
\end{abstract}

Palavras-chave: Equilibração majorante. Programação de computadores. Berçário de hackers. ScratchJr.

\section{ABSTRACT \\ THE MAJORING EQUILIBRATION IN CHILDREN'S EDUCATION: A CASE STUDY}

Computer Programming is a technical competence with potential for human cognitive development. In this sense, it is fundamental to explore its applicability in the elementary school context, a rare theme in scientific production in the area of Education. Thus, the study aimed to identify the relationship between the concept of Majority Equilibrium of Piaget and Computer Programming activities performed by children participating in the Hackers Nursery Project. The methodological procedures used were qualitative research, with a research-action approach, involving participant observation in the workshops and video recordings. The field work was developed with 19 children of five and six years old, being selected two students for a more stopped

* Doutor em Informática na Educação pela Universidade Federal do Rio Grande do Sul (UFRGS). Pós-doutor em Educação pela UFRGS. Atua como pesquisador colaborador no Departamento de Ciência da Formação da Universidade de Roma Três. Pesquisador e líder do Grupo de Pesquisa em Cultura Digital na Educação e responsável pelo programa de extensão Mutirão pela Inclusão Digital, ambos da Universidade de Passo Fundo (UPF). E-mail: teixeira@upf.br

** Mestre em Educação pela Universidade de Passo Fundo. Integrante do Grupo de Pesquisa em Cultura Digital da Universidade de Passo Fundo (UPF). E-mail: carolinesfurini@gmail.com

*** Doutora em Educação pela Universidade Federal do Rio Grande do Sul (UFRGS). Professora titular da Universidade de Passo Fundo (UPF). Líder do Grupo de Estudos e Pesquisa em Educação (Gespe/UPF)) e membro do Grupo Oficinas de História, da Universidade Federal do Rio de Janeiro (UFRJ). 
analysis. The results point to the presence of signs of Major Balance, manifested in active and automatic regulations.

Keywords: Majoring balance. Computer programming. Hackers nursery. ScratchJr.

\section{RESUMEN}

\section{LA EQUILIBRACIÓN MAJORANTE EN NIÑOS DE EDUCACIÓN INFANTIL: UN ESTUDIO DE CASO}

La programación de las computadoras es una competencia técnica con potencial para el desarrollo cognitivo (epistemológico) humano. Es fundamental que sea explorada en ese sentido, en la aplicación del contexto de la educación infantil, un tema raro en la producción científica en el área de Educación. De esta forma el estudio tuvo como objetivo identificar la relación entre el concepto de equilibrio (mejorante) dominante de Jean Piaget con las actividades de programación de computadoras realizadas por niños de educación Infantil participantes del Proyecto Berçeario de Hackeres (cuna de Hackers). Los procedimientos metodológicos utilizados se constituyeron de pesquisa cualitativa, abordando pesquisa - acción incluyendo, observación, participantes en guarderías y videograbación. El trabajo de campo fue desarrollado con 19 niños de cinco años y seis años, siendo seleccionado dos estudiantes para un análisis más profundo, detallado. Los resultados destacaron presencia de indicios de equilibrio "mejorante" evolutivas, manifestadas en formas activas y automáticas.

Palabras clave: El equilibrio evolutivo. Programación de computadoras. Cuna de hackers. ScrachJr.

\section{INTRODUÇÃO}

As concepções de criança e de infância passam por um processo histórico de mudança, representando um avanço e um desafio para o campo da educação. A partir da Lei de Diretrizes e Bases da Educação Nacional (LDB), Lei no . 9394/96, se reconhece a educação infantil como um segmento da educação básica que envolve importante fase do desenvolvimento humano. Assim compreendido, cada vez mais a criança é reconhecida como um sujeito de direitos, que produz cultura, relações, que pensa, cria e descobre. Tal posicionamento, assumido pela Política Nacional de Educação Infantil, exige um novo olhar para essa etapa de ensino (MACHADO, 2011).

Esse pressupõe uma ampliação da visão de infância e a busca de novas formas de ensinar e aprender na educação infantil. Nessa direção, esse campo de estudos tem direcionado esforços para a exploração de diferentes recursos tecnológicos. As tecnologias computacionais, nessa direção, representam um campo vasto, porém pouco pesquisado no que concerne a crianças pequenas, sendo esse um campo que se mostra lacunar. Ao se realizar o estado da arte dessa temática (GOMES, 2010; MACHADO, 2011; ROCHA, 2010; SANTOS, 2007; SILVA, 2010), constatou-se que as pesquisas trabalham, essencialmente, com a perspectiva do hardware, ou seja, a parte física da tecnologia.

Contribuindo com essa condição está a programação de computadores, direcionamento ainda pouco discutido, especialmente para essa faixa etária. Assim sendo, com este estudo pretende-se contribuir com o avanço do conhecimento acerca das potencialidades da programação de computadores para crianças, nesse caso específico, investigando como essa atividade incide sobre os processos de equilibração majorante. Esses se caracterizam por corrigir e preencher outras formas de equilíbrio a partir da auto-organização do sujeito, conforme conceito cunhado por Piaget (1976).

Dessa forma, o estudo se propõe a responder a seguinte questão: como se manifestam os processos 
de regulações ativas e automáticas de crianças de cinco e seis anos, tendo em vista a identificação de evidências de equilibrações majorantes, mediante a ação em atividades de programação de computadores realizadas no âmbito do Projeto Berçário de Hackers? Para aproximar respostas a essa interrogação, o estudo constituiu-se, metodologicamente, em uma pesquisa qualitativa, caracterizada como pesquisa-ação, com dados primários produzidos por meio de observação participante e videogravações nas oficinas do Projeto Berçário de Hackers - programa realizado na Universidade de Passo Fundo, com crianças de escolas de educação infantil da rede pública municipal de Passo Fundo, Rio Grande do Sul. O grupo-sujeito da pesquisa constituiu-se de 19 crianças da educação infantil, na faixa etária de cinco e seis anos, participantes do referido programa.

Assim, este artigo é apresentado, inicialmente, discutindo-se modelos pedagógicos e epistemológicos da cognição humana, destacando-se a apresentação do conceito de equilibração majorante, com base em Piaget (1976) e apoiando-se, ainda, em intérpretes dessa teoria, como Montangero e Maurice-Naville (1998) e Becker (2001). Na sequência, pela visão de Papert (1994), Bruner (2001) e Veen e Vrakking (2009), buscou-se entender as implicações do uso das tecnologias, especificamente da programação de computadores, para crianças de educação infantil, reconhecendo a execução das linhas de código como uma potencial obra que expressa os pensamentos da criança e, ainda, investigando possíveis manifestações de equilibração majorante em atividades direcionadas pela programação de computadores. Em continuidade, apresentou-se o percurso metodológico seguindo-se com a apresentação e discussão dos resultados e as considerações finais.

\section{MODELOS PEDAGÓGICOS E EPISTEMOLÓGICOS DA COGNIÇÃO HUMANA}

As diferentes teorias sobre a cognição humana foram gestadas tanto sobre espaços formais de ensino, quanto sobre espaços informais. No que diz respeito aos primeiros, Becker (2001) sistematiza três principais modelos pedagógicos: a pedagogia não-diretiva, a pedagogia diretiva e a pedagogia relacional.

A pedagogia não-diretiva apresenta características do professor, meio e objeto, como facilitadores e auxiliadores do estudante, que, por sua vez, aprende por si mesmo, a partir de sua bagagem hereditária. Mediante essa premissa, a intervenção docente é minimizada, pois o sujeito já possui o potencial do conhecimento, que só precisa vir à consciência e ser organizado. Tal modelo pedagógico possui vertentes de uma epistemologia apriorista, que remonta a Platão (427-347 a.C.). Ele acreditou, grosso modo, que o sujeito não aprende nada novo, pois está predeterminado. Tudo o que o indivíduo será já está concebido, seja pela bagagem hereditária ou alma, e esse precisa apenas refletir para descobrir o que está dentro de si.

$\mathrm{Na}$ pedagogia diretiva acontece o oposto ao mencionado anteriormente, pois o sujeito é visto como dependente, ou seja, determinado pelo mundo, não tendo a possibilidade de desenvolver criticidade, criatividade e curiosidade, já que o meio oferece tudo o que ele não possui e que irá adquirir. Assim, o conhecimento é visto como uma transmissão. Esse modelo pedagógico tem proximidade com o empirismo, corrente epistemológica que foi iniciada por Aristóteles (384-322 a.C.) e que pressupõe a importância da experiência sensorial para a descoberta de conhecimentos. O homem é considerado uma "tábula rasa" e suas vivências vão lhe imprimir os primeiros sentidos.

Por fim, Becker (2001) cita o modelo pedagógico relacional, tendo como princípio a construção mútua entre sujeito e meio, professor e estudante. "Tudo o que o aluno construiu até hoje em sua vida serve de patamar para continuar a construir [...] alguma porta se abrirá para o novo conhecimento - é só questão de descobri-la; ele descobre isso por construção" (BECKER, 2001, p. 24). De acordo com tais princípios, o professor acredita na necessidade de problematizar a ação do estudante para, assim, fomentar aprendizagens. Isso porque através da ação ele é capaz de criar algo novo dentro de si por meio da constituição da consciência sobre o que fez. A pedagogia relacional também foi pensada por Becker (2001), a partir de uma vertente da matriz construtivista. 
O construtivismo, de acordo com Piaget (1976), coloca-se em oposição à crença do papel preeminente das contribuições sociais ou de capacidades inatas do sujeito e julga que o conhecimento se dá na interação entre ambos e que nunca está findado. Assim, Piaget destinou como central em sua teoria a ação do sujeito como um elemento essencial para que o conhecimento se estruture em interação com o meio. Dessa forma, acreditou que a consciência vinha à tona no sujeito após uma complexa operação, envolvendo a realização de uma ação e a recriação de conhecimentos já existentes, possibilitando a criação de novos caminhos ao conhecimento e impulsionando a história do sujeito e do seu meio.

Piaget (1976), nesse sentido, tinha uma visão que foi sendo ressignificada com o passar do tempo, compondo a compreensão de que todo sujeito efetua um equilíbrio imperfeito sobre o seu próprio conhecimento, que é fruto de constantes mudanças. Nessa dinâmica, a tendência é de um equilíbrio melhor, após um desequilíbrio inicial, e esse movimento é que permite a evolução do conhecimento. Toma corpo, assim, a essencialidade da equilibração majorante.

\subsection{A equilibração majorante dos sistemas cognitivos}

A obra de Piaget intitulada $A$ equilibração das estruturas cognitivas, datada de 1976 , tem como objetivo explicitar a gênese e o desenvolvimento do conhecimento através da equilibração. Esse conceito apareceu no terceiro período da obra do autor, porém, é no quarto período que o processo da equilibração é detalhado. Nesse momento o autor fala de equilibrações majorantes, que se caracterizam por corrigir e preencher as formas anteriores de equilíbrio a partir da auto-organização do sujeito (PIAGET, 1976).

São vários os processos que a tornam possível, sendo imprescindível entender que existem diversas formas de equilíbrio, que passam por diferentes desequilíbrios e reequilibrações. O equilíbrio dos sistemas cognitivos é caracterizado pela dinamicidade com que o sujeito realiza trocas com o meio, porém fechado em ciclos. As partes constituintes de um ciclo e que ajudam o sujeito a refletir sobre cada situação do meio são apresentadas como A, B, C, por exemplo. Já os elementos que alimentam esse ciclo são denominados de A', B', C', e seguintes, obtendo-se a forma esquemática proposta por Piaget (1976):

$$
\left(\mathrm{AxA}^{\prime}\right) \rightarrow \mathrm{B} ;\left(\mathrm{B} \times \mathrm{B}^{\prime}\right) \rightarrow \mathrm{C} ; \ldots ;\left(\mathrm{Z} \times \mathrm{Z}^{\prime}\right) \rightarrow \mathrm{A} \text { etc. }
$$

No esquema em foco existe certa ação conservadora que os elementos ou subsistemas exercem uns sobre os outros. Quando acontece uma perturbação exterior, o ciclo reage de forma diferente: pode haver a impossibilidade de uma conservação do estado anterior e rejeição ou morte do organismo, ou também pode acontecer uma modificação do estado que compensa o ciclo já constituído, ocorrendo uma adaptação ou um novo equilíbrio. Dessa maneira, o equilíbrio pode ser caracterizado por diferenciações e integrações. Piaget (1976) chama atenção para o funcionamento desses ciclos, afirmando que estão relacionados a dois processos que permitirão o progresso de toda a equilibração: a assimilação e a acomodação.

O conceito de assimilação é analisado por Montangero e Maurice-Naville (1998), que elucidam como sua noção dá ênfase à atividade do sujeito em seu processo de conhecimento. Esse, ao agir sobre a realidade ou sobre os seus pensamentos e conceitos já desenvolvidos e ao integrá-los às estruturas mentais, está a desenvolver o conhecimento. A assimilação representa, dessa forma, a ação do sujeito sobre o objeto/meio. Nessa ação, o sujeito integra os conhecimentos novos às estruturas que já possuía, construindo, progressivamente, esquemas para cada situação.

No ato de conhecer, o sujeito age sobre o objeto e sua ação se transforma. Todavia, há momentos em que o objeto resiste aos instrumentos de assimilação disponíveis, levando o indivíduo a aperfeiçoar-se ou a reorganizar-se, sendo capaz de assimilar objetos cada vez mais complexos. Assimilação e acomodação passam a ser interdependentes e conservam as aquisições novas, conciliando com as antigas. Dessa maneira, conhecer pode tanto transformar o objeto, quanto a si mesmo. É nesse quesito que aparece o segundo postulado, sobre o qual Piaget (1976, p. 14) afirma que "todo esquema de assimilação é obrigado a se acomodar aos 
elementos que assimila, isto é, a se modificar em função de suas particularidades, mas, sem com isso, perder sua continuidade [...], nem seus poderes anteriores de assimilação", afirmando a necessidade de equilíbrio entre ambos.

Como vê-se na Figura 1, os elementos A, B e $\mathrm{C}$ representam o sistema cognitivo do sujeito e a maneira como realizam suas assimilações; os elementos A', B' e C' representam, por sua vez, os objetos externos que se apresentam como complementares ou modificadores do sujeito. Em um primeiro momento, o elemento exterior A' encaixa-se perfeitamente ao seu correspondente $\mathrm{A}$, o que não acontece com a acomodação do segundo elemento, C', que possui particularidades diferentes de $\mathrm{C}$ e que irá pressionar o sujeito para, no decorrer da ação, sofrer modificações.

Montangero e Maurice-Naville (1998) também analisam a acomodação como a relação do sujeito com o objeto de conhecimento, ou seja, é esse conceito que demarca a ação do meio. Essa relação pode promover melhorias no esquema do sujeito ou, então, pode trazer diferenças inconciliáveis, provocando a elaboração de novos esquemas. Nesse sentido, a acomodação produz uma mudança, grande ou pequena, mas que faz com que o indivíduo sinta a ação do meio e passe a ajustar seus esquemas aos novos modos do saber. Seria a ação do objeto/meio sobre o sujeito. Acomodação e assimilação são, portanto, indissociáveis, são polos de uma mesma interação do organismo com o meio.

Em meio a esses dois polos encontram-se os desequilíbrios, como alavanca para uma nova equilibração. "Numa perspectiva de equilibração, uma das fontes de progresso no desenvolvimento dos conhecimentos deve ser procurada nos desequilíbrios como tais, que por si só obrigam um sujeito a ultrapassar seu estado atual e a procurar o que quer que seja em direções novas" (PIAGET, 1976, p. 18), condição que se busca expressar na Figura 1.

Figura 1 - Processo de assimilação e acomodação de elementos externos.

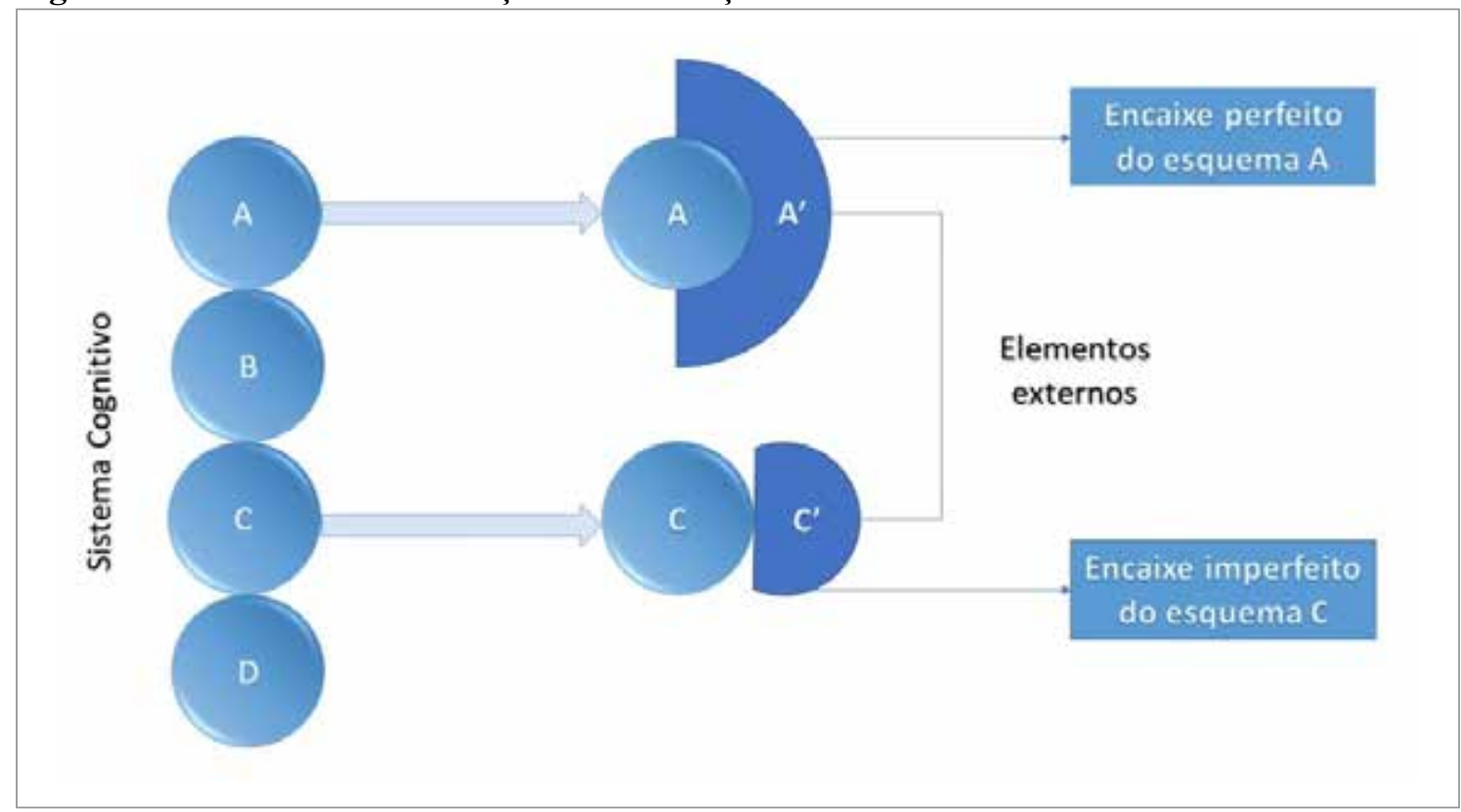

Fonte: Elaborado pelos autores deste artigo.

No entanto, apesar de constituírem algo relevante no processo e não permitirem uma imobilidade do conhecimento, a chave do desequilíbrio é sua própria superação. Ele só tem sentido a partir do momento em que desencadeia a saída de determinado estado em busca de uma reequilibra- ção, fonte real do progresso. As reequilibrações representam, então, não a volta ao estado anterior, mas a modificação dos esquemas do sujeito e seu melhoramento.

Sobre esse processo incidem as regulações, que definem o "como" da equilibração e das re- 
equilibrações. A regulação pode ser manifesta de duas maneiras: quando acontece uma correção do sistema cognitivo A pelo elemento externo A' (feedback é negativo) e quando ocorre o feedback positivo. No primeiro caso o sujeito é submetido a um repensar dos conhecimentos e com isso gera-se uma certa resistência, todavia transformada em uma mudança. Entretanto, no segundo caso, acontece um reforço do sistema cognitivo, podendo até haver o crescimento da lacuna causada pela falta de algum conhecimento, o feedback é positivo, mantendo o sujeito em estabilidade.

Fazem parte também desse movimento as perturbações, definidas "como algo que serve de obstáculo a uma assimilação, tal como atingir um objetivo, todas as regulações são, do ponto de vista do sujeito, reações a perturbações" (PIAGET, 1976, p. 24), ou seja, a perturbação age sobre o sujeito que se utiliza de regulações para reagir aos primeiros sinais desse desconforto. As perturbações que se opõem à acomodação - feedback negativo - resistem ao objeto e causam fracassos ou erros, com posteriores correções. Já as perturbações que são lacunas - feedback positivo - deixam insatisfeitas as necessidades e não alimentam suficientemente o esquema.

Com relação à reciprocidade entre regulação e perturbação, Piaget (1976, p. 25) ressalta que "não poderíamos falar de regulação quando a perturbação provoca simplesmente uma repetição da ação, sem qualquer mudança, e com a ilusória esperança de ser melhor sucedida". Assim, a regulação acontece quando há a presença de um regulador. Tanto o equilíbrio mais amplo proporcionado pelas regulações, quanto a estabilidade ocasionada, que não deixa de construir negações, são importantes para o processo de evolução dos esquemas e possibilitam progressos rumo ao equilíbrio.

Manifesta-se que, assim como nem toda perturbação gera regulações, nem todas as regulações produzem compensação. Quando acontece a compensação de algo com sentido contrário, anulando-o ou mesmo neutralizando-o, os feedbacks negativos agem como instrumentos de correção que, de modo geral, sempre conduzem à compensação. Nesse sentido complementa-se, em Piaget (1976, p. 31, grifo nosso), que
[...] de modo geral, as regulações por feedbacks negativos conduzem sempre a compensações, entre as quais se podem distinguir duas classes: as compensações por 'inversão', que consistem na anulação da perturbação, e as compensações por 'reciprocidade', que diferenciam o esquema para acomodá-lo ao elemento inicialmente perturbador. As primeiras implicam, pois, em negações inteiras e as segundas em negações parciais, mas desta vez internas, no meio do novo sistema assim reestruturado.

Tanto as negações inteiras quanto as negações parciais reestruturam os esquemas. Embora os esquemas tendam a melhorar sequencialmente, proporcionando o equilíbrio do sujeito com o meio, as perturbações e negações são essenciais à reestruturação e ao processo de aprendizagem.

Outro fator de compensação, embora ocorra de maneira mais complexa, é o feedback positivo. Quando os obstáculos exteriores são contornados, acontece o retorno ao erro, à perturbação, tendo o feedback positivo reforçado a lacuna que, na definição de Piaget, também não deixa de ser uma compensação, já que mesmo sendo um reforço, implica em dificuldades e, logo, em correção. Piaget afirmou que os feedbacks positivos estão interligados aos negativos e suas compensações, pois as mudanças requerem ao mesmo tempo reforço e correção. Na mesma linha, afirma que "o reforço devido ao feedback positivo está destinado a preencher uma lacuna [...] ora, preencher uma lacuna é uma compensação, segundo a definição adotada" (PIAGET, 1976, p. 32). O fator principal da formação de um feedback positivo é o valor que o sujeito atribui a uma meta, dessa forma, a necessidade representaria um desequilíbrio e a satisfação uma reequilibração.

Até o momento abordou-se diferentes conceitos que constituem o processo total da equilibração majorante. Salienta-se, assim, que a constituição desse processo não é linear, tampouco obedece a um ritmo constante. Contudo, todos os conceitos viabilizam a equilibração das estruturas cognitivas do sujeito. A própria denominação dada por Piaget já indica que, ao invés de um equilíbrio, sua teoria buscou uma equilibração, ou seja, nunca um ponto de parada, mas um movimento em que todas as resoluções precedentes servem para levantar novos problemas. Acontecem, com isso, melhoramentos 
nos equilíbrios cognitivos por meio das construções que vão ocorrendo e, a partir dessas, a superação das construções anteriores.

Nesse sentido, um sistema nunca está acabado, novos objetivos surgem de um equilíbrio instável ou estável e pleno de aberturas. Dessa maneira, a equilibração não é uma marcha para um equilíbrio, sobretudo, é uma estruturação para um melhor equilíbrio. Assim, a majoração pode ser definida como um equilíbrio conquistado momentaneamente ou como novidades retiradas das próprias regulações. Por assim considerar, o melhoramento pode acontecer quando um elemento que causa perturbação ao indivíduo acaba por ser assimilado. O que antes não permitia uma acomodação, agora acrescenta ao esquema do sujeito uma extensão maior. Um segundo aspecto do avanço aponta que o êxito das regulações compensadoras não apenas amplia a extensão do esquema, mas resulta em diferenciações. A terceira forma de enriquecimento da equilibração acontece por meio da ampliação das acomodações e formação de novos subsistemas.

Compreende-se, assim, que a equilibração majorante é composta por variadas formas. Para Piaget (1976), a construção gradativa de negações é considerada o enriquecimento mais importante, causador de uma carência inicial que transformar-se-á em equilíbrio. Depreende-se, então, que a equilibração majorante é a constituição de várias partes importantes que se complementam, possuindo a característica de ampliar os esquemas do sujeito para, dessa forma, caminhar em direção a um desenvolvimento cada vez mais aperfeiçoado. O papel do desequilíbrio é essencial para que o sujeito possa vir a pensar sobre o seu próprio conhecimento e, então, reorganizá-lo, ou mesmo persistir no erro e posteriormente pensar sobre a desestabilidade ocasionada. A partir do pensamento sobre as próprias dificuldades, o indivíduo busca maneiras de compensar essa perturbação e uma nova construção acontece, trazendo consigo o melhoramento do ciclo que compõe o sistema cognitivo. São essas perspectivas que conduzem a pensar sobre as possibilidades que a programação de computadores representa para o desenvolvimento cognitivo de crianças, especialmente em contextos de educação infantil.

\section{A INFÂNCIA, A EDUCAÇÃO E AS TECNOLOGIAS DIGITAIS}

Nas seções anteriores visualizou-se o quanto a teoria de Jean Piaget contribui para as pesquisas referentes ao sistema cognitivo dos sujeitos e à construção de suas aprendizagens. A partir do estudo da equilibração majorante é que se inicia a discussão sobre como a programação de computadores e as atividades que a envolvem podem auxiliar no desenvolvimento dos esquemas do sujeito.

O contexto atual de educação é muito diferente do vivido no século passado, e isso porque os estudantes chegam às escolas apresentando novas demandas aos profissionais docentes. As Tecnologias de Informação e Comunicação (TICs) têm colocado aos sujeitos que experienciam os processos educativos escolares uma nova forma de visualização da própria vida, apresentando-se como importantes para a resolução de variadas situações, formais e informais, de ensino. Nessa direção, Veen e Vrakking (2009, p. 21) observam que

[...] vemos este mundo que criamos, cuja interação global é rápida, por meio da mídia e da tecnologia da comunicação, e reconhecemos que não poderíamos sequer chegar perto de tal velocidade ou ter tanta informação se não dispuséssemos do que dispomos. De certa forma, o mundo de hoje não seria possível sem a tecnologia da comunicação disponível para a maior parte das pessoas.

Nesse cenário, o ensino tornou-se uma tarefa mais desafiadora em razão da mudança dos estudantes quanto às aprendizagens, aos comportamentos e pensamentos. A geração de estudantes que chegam às escolas, denominada por Veen e Vrakking (2009) de Homo zappiens, é uma geração que adotou o computador e a tecnologia digital em geral como parte integrante de suas vidas. Tudo passou a ter uma velocidade absurdamente maior do que anteriormente. A busca pelo entendimento da nova geração é capaz de ressignificar os modos de ver a aprendizagem e o sistema educacional, colocando tais tecnologias como parte da discussão e do debate de como o ensino se desenvolve.

Os processos educativos sempre dependeram de tecnologias para seu suporte, sendo que estas construíram-se com o objetivo de tornar os espaços de ensino protagonistas de pensamentos com foco 
na ação dos estudantes. Todavia, se forem utilizadas apenas com o intuito de inovação, logo esvaziam-se de significado. Pesquisadores brasileiros do campo educacional também têm prestado atenção aos novos cenários. Bonilla (2005, p. 12) afirma que "as novas tecnologias estão sendo recebidas e usadas de acordo com os significados que foram construídos em torno da tecnologia anterior - lápis e papel”. Tal afirmação traz consigo o posicionamento de que a tecnologia digital não tem representado uma mudança no cenário, e sim utilizada de modo a preservar modelos de ensino vivenciados pelos professores, quando estudantes.

O referido autor destaca, ainda, que a internet, por exemplo, é vista por muitos professores como mais uma ferramenta para facilitar o acesso às informações, sem necessariamente alterar suas concepções e práticas metodológicas. Assim sendo, em meio a todo esse panorama de progresso tecnológico global e da aparente estagnação dos contextos escolares, faz-se necessário pensar na criança de hoje e no modo como aprende, compreende e desenvolve-se cognitivamente.

Desde há muito tempo o conceito de criança vem se ampliando e a infância vem sendo objeto de estudos especializados, compreendida como um período definidor na vida do ser humano. Sabe-se que as construções realizadas na primeira infância serão base para tudo o que for apreendido a partir de então. A Constituição Federal de 1988 (BRASIL, 1988) estabelece que o atendimento em creches e pré-escolas é direito social de toda criança, prerrogativa que foi conquistada pela luta coletiva de movimentos comunitários, de trabalhadores, mulheres e dos próprios profissionais da educação. Desde então, o desenvolvimento das crianças e a educação para elas direcionada começou a se modificar e fortalecer-se. Reconheceu-se a educação infantil como um período rico em aprendizagem e o trabalho com crianças de até três anos em creches e de quatro e cinco anos em pré-escolas, ${ }^{1}$

1 Com a Constituição Federal de 1988, o atendimento em creche e pré-escola às crianças de zero a seis anos de idade se torna dever do Estado. Posteriormente, com a promulgação da LDB, em 1996, a educação infantil passa a ser parte integrante da educação básica, situando-se no mesmo patamar que o ensino fundamental e o ensino médio. A partir da modificação introduzida na LDB em 2006, que antecipou o acesso ao ensino fundamental para os seis anos de idade, a educação infantil passa a atender a faixa etária de zero a cinco anos e passa a ser obrigatória para as crianças como repleto de conhecimento e não apenas com o dever de cuidado. A criança passou a ser concebida, segundo as Diretrizes Curriculares Nacionais Para a Educação Infantil (DCNEIs), como um

[...] sujeito histórico e de direitos que, nas interações, relações e práticas cotidianas que vivencia, constrói sua identidade pessoal e coletiva, brinca, imagina, fantasia, deseja, aprende, observa, experimenta, narra, questiona e constrói sentidos sobre a natureza e a sociedade, produzindo cultura. (BRASIL, 2010, p. 12).

Esse trecho evidencia uma nova visão de criança. Diferentemente de ser considerada um "pequeno adulto" ou de estar sendo preparada apenas para a vida adulta ou para os níveis maiores de escolaridade, é concebida de acordo com as suas necessidades e peculiaridades. Isso infere considerar seu potencial de fala e ação, seus direitos e deveres, enfim, seu desenvolvimento integral e sua autonomia. Ainda, diante dessa nova concepção, a criança é entendida como protagonista, produtora de conhecimento e cultura e, por isso, a grande demanda que se apresenta é a de uma educação pensada para a ampliação do desenvolvimento dos pequenos.

Considerar essa nova condição pressupõe ponderar sobre o modo como as TICs são concebidas e utilizadas na escola que acolhe tais crianças, uma vez que elas estão naturalmente presentes nas suas vidas, fomentando novas maneiras de aprender e de conhecer. Nesse contexto de intensas conexões e compartilhamentos, os estudantes têm acesso ao mundo e, forçoso reconhecer, com essas características é que estão ingressando nas escolas. Veen e Vrakking (2009, p. 47) acreditam que "o modo de ser do Homo zappiens é digital, e não analógico. Suas estratégias de aprendizagem, por isso, mudaram - se aceitarmos que por meio de jogos de computador e da comunicação com outras crianças de fato se aprende".

Com base nesse pressuposto, pode-se entender que as crianças descobrem o mundo de diversas maneiras, sejam elas digitais ou analógicas, e todas

de quatro e cinco anos por meio da Emenda Constitucional $\mathrm{n}^{\mathrm{o}}$ 59/2009. Essa extensão da obrigatoriedade foi incluída na LDB em 2013, consagrando plenamente a obrigatoriedade de matrícula de todas as crianças de quatro e cinco anos em instituições de educação infantil (BRASIL, 2017, p. 31). 
são pertinentes às aprendizagens. Entretanto, as aprendizagens digitais possibilitam características diferentes de sistematização do saber. No estudo de Veen e Vrakking (2009, p. 53) são descritas algumas capacidades relacionadas à aprendizagem, desenvolvidas por crianças a partir do manuseio das tecnologias. Dentre elas, os autores destacam a habilidade icônica, associada à maneira como buscam informações no mundo multimídia. Ao navegarem pela internet, as crianças demonstram rapidez e exatidão, por terem familiaridade com o colorido de imagens, textos, ícones, links, dentre outros.

A grande quantidade de informações disponíveis e acessíveis é uma realidade das sociedades contemporâneas, disseminando-se de tal forma que não é uma possibilidade apenas para alguns, tendo o seu alcance amplificado e massificado: há informação em abundância. Aprender a selecionar informações e ter a capacidade de lidar com essa profusão é algo que precisa ser muito bem estruturado no universo das crianças. "Se não for assim, elas correm o risco de ficar sobrecarregadas e de não ter tempo para ir até o detalhe de buscar informações que devam primeiramente ser estudadas e refletidas em maior profundidade" (VEEN; VRAKKING, 2009, p. 54).

Outra capacidade destacada pelos autores é a execução de múltiplas tarefas. Todavia, tal abordagem requer uma análise de maior alcance, isso porque estudos relacionados à neurociência apontam que "a aprendizagem depende da intensidade da atenção. [...] Para prestar a atenção em algo é necessário 'filtrar' o que se percebe, ou seja, escolher o objeto de percepção" (LIMA, 2007, p. 22). Essa premissa leva a compreender que o cérebro humano seleciona aspectos sobre os quais se deter em cada momento, modulando diferentes níveis de atenção a cada atividade e não as realizando ao mesmo tempo. Lima (2007, p. 8) afirma ainda que o cérebro funciona integradamente:

É comum a articulação de várias áreas para um só comportamento. A formação de uma imagem no cérebro requer a utilização de várias áreas, pois forma, cor, posição no espaço, uso e movimentação são processados separadamente. Para falar, usamos várias áreas, incluindo os centros de linguagem, que estão no hemisfério esquerdo, e áreas que processam a música, que estão do lado direito. Estudos recentes sugerem que para o ato de ler são mobilizadas dezessete áreas no cérebro.

Por fim, as tecnologias digitais favorecem, ainda, as habilidades colaborativas, que não eram tão presentes quando surgiram os primeiros computadores, por serem esses dispositivos para uso individual. Contudo, com o passar do tempo e com as evoluções que aconteceram nos jogos, o computador passou a ser reconhecido como um espaço de apoio mútuo. Segundo Veen e Vrakking (2009, p. 69), as crianças parecem entender através dos jogos que esse apoio é essencial para a resolução de problemas, "elas aprendem que a competição é outra estratégia e é a situação que determina qual estratégia é a mais eficaz".

Quando se está em um jogo com mais pessoas, o que não implica estar perto fisicamente, há estratégias que não se cumprem solitariamente, mas precisam dos outros jogadores para serem efetivadas. $\mathrm{O}$ mesmo acontece presencialmente; há momentos em que algumas crianças se sobressaem e auxiliam aquelas que ainda não reconheceram os espaços do jogo. Veen e Vrakking (2009, p. 36) completam que:

A maior parte dos jovens começa a jogar aos 3 anos. Há muitos jogos simples nas lojas hoje, e, antes de entrar na pré-escola, a criança já terá aprendido os princípios fundamentais da matemática, saberá reconhecer formas e Figuras retangulares, circulares e piramidais e como pagar por mercadorias ao fazer compras, como classificar ou montar objetos e como usar o computador ou manipular o teclado. Para o Homo zappiens, a aprendizagem começa com uma brincadeira e se trata de uma brincadeira exploratória por meio dos jogos de computador.

Tal colocação leva a refletir sobre o perfil dos estudantes da educação infantil e desse contexto escolar. A escola pública brasileira ainda recebe crianças que terão contato com a tecnologia somente no espaço formal de ensino. Possivelmente, ao manusearem as ferramentas que lhes forem apresentadas, logo compreenderão a tecnologia, pois, como vê-se em Lima (2007, p. 15), "quanto mais novo o ser humano, maior plasticidade seu cérebro apresenta. Certas conexões se fazem com uma rapidez muito grande na criança pequena". Assim sendo, parece ser um papel e um compro- 
misso da escola atual o de oferecer e potencializar o uso das tecnologias digitais, de modo a fomentar o desenvolvimento da criança, considerando o seu protagonismo nos processos de aprender. Para tanto, a programação de computadores aparece como viável à potencialização de aprendizagens.

\subsection{A programação de computadores como uma alternativa de potencialização das aprendizagens}

A popularização dos ambientes de programação para crianças vem avançando ao longo dos anos. O primeiro grande impulsionador da informática educativa e, após isso, da programação de computadores foi Seymour Papert. Em seu livro A Máquina das Crianças - Repensando a Escola na Era da Informática (PAPERT, 1994), ele traça seu próprio percurso enquanto adulto até o contato com a tecnologia. Destaca que o computador lhe fez voltar aos tempos de criança e se maravilhar por algo, como se encantara pelos brinquedos quando pequeno.

Dentre as diversas reflexões que desenvolve em seus estudos, Papert (1994, p. 19) destaca que "embora tenha sempre ansiado por 'estilos de aprender' nos quais as crianças agem como criadores ao invés de consumidores do conhecimento, os métodos propostos sempre me pareceram apenas um pouco diferentes, quando muito, dos estilos antigos". Observa-se, assim, que Papert (1994) se preocupou em tornar a aprendizagem um processo pessoal e com significado e, por isso, deu início a um novo momento para o uso das tecnologias, desenvolvendo um ambiente que pudesse ser trabalhado nas escolas.

Ele acreditava que "aprender-em-uso libera os estudantes para aprender de uma forma pessoal, e isso, por sua vez, libera os professores para oferecer aos seus alunos algo mais pessoal e mais gratificante para ambos os lados" (PAPERT, 1994, p. 62). Para efetivar tais concepções educativas, propôs que a criança aprenderia melhor se tivesse a tarefa de ensinar o computador, ou seja, se o programasse. A programação de computadores, segundo Papert (1994), oportunizaria à criança um tempo para pensar sobre os problemas a resolver. A chave da aprendizagem estaria no tempo para refletir sobre as situações e não na pressa em resolver tudo de uma vez, característica muito presente em determinados modelos pedagógicos. Quando o autor viu as crianças brincando com sua criação, o LOGO, a ser detalhado a seguir, teve como retorno a resposta eufórica dessas.

\subsubsection{O percurso dos softwares educativos de programação até o ScratchJr}

O software LOGO foi criado por Papert em 1967, mas chegou ao Brasil apenas na década de 1980. Toda sua interface desenvolve-se a partir de uma tartaruga guiada por comandos - para frente, para a direita, para trás, repita, entre outros - programáveis. Tais comandos de direção favorecem "a ideia de que os números representam a distância que ela se move - eles podem ser pensados como passos de tartaruga" (PAPERT, 1994, p. 35). O autor acrescenta que "em algum lugar, você encontrará seu nível de dificuldade e, quando o encontrar, eu lhe darei este conselho: coloque-se no lugar da tartaruga. Imagine se movimentando em um quadrado ou em um círculo ou em um espiral ou seja o que for" (PAPERT, 1994, p. 35).

A interface de LOGO possui uma janela gráfica onde acontece a programação e também a janela de comandos, que permite aos estudantes fazerem direcionamentos à tartaruga através dos comandos, sendo que a numeração é que definirá os ângulos e, consequentemente, a imagem que a tartaruga irá formar. Como se pode perceber, a linguagem LOGO adentrou as escolas como uma revolução na forma de ver o computador e, em sua época, foi definidora para entender que os computadores poderiam, sim, melhorar as aprendizagens escolares, se bem utilizados. Envolveu conceitos importantes e uma aprendizagem prazerosa, podendo-se criar diferentes programações para a tartaruga. Todavia, com o passar dos anos, começou a ficar limitada enquanto plataforma.

Assim, avanços consideráveis foram estabelecendo-se e com novos impulsos intelectuais surge o Scratch, pensado para um público similar ao de LOGO, todavia com uma interface mais amigável e intuitiva e com muito mais opções de programação. Criado em 2007, o Scratch foi idealizado por Mitchel Resnick, também pesqui- 
sador do Massachusetts Institute of Technology (MIT), e projetado para um público com idades entre oito e 16 anos.

$\mathrm{Na}$ interface do Scratch, o palco (local onde acontece a programação) e os comandos ganharam cores e tornaram-se mais atrativos. Para além dos comandos de direção, inseriu-se comandos de aparência, som e variáveis, representando uma evolução. No entanto, tal software ainda era inviável para a educação infantil. Surge, assim, o ScratchJr, criado por Mitchel Resnick e Marina Bers, que chegou ao Brasil em 2014, com uma plataforma totalmente voltada para as crianças em processo de alfabetização, abrindo uma variedade de opções de criação para esse segmento da escolarização, composto por crianças de zero a cinco anos.
Queiroz (2012) menciona que os criadores do ScratchJr acreditaram na programação de computadores como um novo tipo de alfabetização, sendo que, quando pequenas, as crianças iniciam suas programações e vão aperfeiçoando-as com o amadurecimento. A diferença notável no ScratchJr é a possibilidade de leitura através de símbolos e cores. Os personagens são caricaturados para lembrar a infância e, dessa forma, aumentar o desejo por brincar com os blocos de programação. Inúmeras são as possibilidades oferecidas pelo ScratchJr, permitindo a criação de histórias, animações e, sobretudo, o desenvolvimento de conceitos importantes para as aprendizagens futuras. Na Figura 2 pode-se observar as diferentes partes do software que permitem a criação das programações.

Figura 2 - Interfaces do ScratchJr.

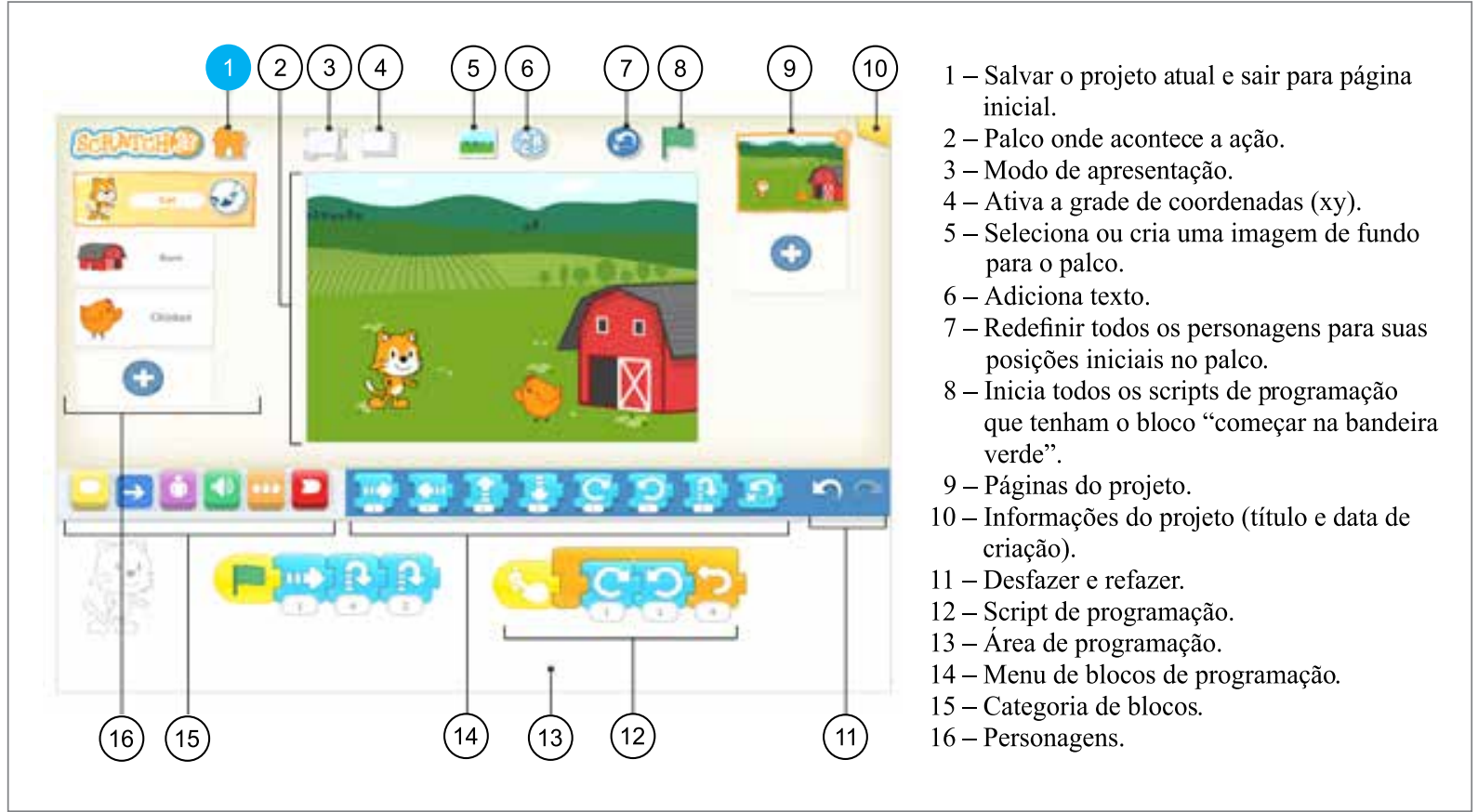

Fonte: Adaptado de ScratchJr (2017).

Analisando-se a Figura 2, percebe-se que o ScratchJr oferece blocos para viabilizar a programação. Manuseando as ferramentas, as crianças vão descobrindo as potencialidades que essas lhes oferecem, ou seja, a ação é definidora para que a tecnologia não seja vista como um fim em si mesma. A ação da criança, nesse software, exige sua reflexão e a externalização de seu pensamento. Nes- sa direção toma-se Bruner (2001), quando enfatiza que a externalização do pensamento gera uma obra.

$\mathrm{O}$ autor acredita que a função da obra é a construção de uma identidade pessoal e, também, o encontro com sua comunidade, sendo que "a externalização produz um registro de nossos esforços mentais, um registro que fica 'fora de nós', e não vagamente 'na memória'. É algo parecido como 
produzir um rascunho, um esboço, uma 'maquete"' (BRUNER, 2001, p. 31, grifo nosso). Essa externalização do pensamento auxilia no reconhecimento da comunidade e dos sistemas simbólicos produzidos nela, isso porque, nos momentos em que o sujeito externaliza tudo aquilo que experiencia em pensamento, é possível que se conecte à comunidade, que passa a entender seus valores e criações, tendo na obra a realização desse processo.

Em um contexto de tecnologias educacionais, pode-se pensar no ato de programar - como o oferecido pelo ScratchJr - como uma obra em construção, tratando-se de transcrições do pensamento em códigos de programação, a fim de repassar àqueles comandos desejos de movimentos corporais, bem como de características do meio. Papert acreditou no conhecimento como uma construção e, nesse sentido, considerou que a melhor forma que as crianças dispõem para conhecer é através da descoberta e que "a educação organizada ou informal pode ajudar, principalmente, certificando-se de que elas sejam apoiadas moral, psicológica, material e intelectualmente em seus esforços" (PAPERT, 1994, p. 125). Para esse autor, por meio da programação de computadores os pensamentos são potencializados no produto, em andamento e em estado final, tendo em um software o meio para que isso se torne possível.

Na mesma direção, Bruner (2001, p. 32) afirma que "o pensar se realiza em seus produtos", na medida em que o produto permite, de maneira mais incorporada, a reflexão sobre os próprios pensamentos. O preceito bruneriano da externalização e a teoria construcionista de Papert encontraram no produto a realização dos pensamentos, bem como a satisfação do reconhecimento da comunidade. Há singularidade por ser a descoberta de uma obra pessoal. A obra acaba tornando-se um manifesto dos pensamentos mais íntimos e incompreensíveis e auxilia na trajetória até a compreensão. Seu significado pode não ser percebido no exato momento em que a obra foi concluída, porém os efeitos de tal vivência podem trazer significativas transformações nos desenvolvimentos que virão, tanto em uma identidade pessoal quanto comunitária.

Assim como a programação de computadores realiza-se na obra construída pelo sujeito, existe outro fator que é uma premissa essencial para que a programação seja executada. Wing (2006 apud RAMOS, 2014, p. 31) reconhece-o como pensamento computacional e afirma que

[...] abrange desde a resolução de problemas até a compreensão do comportamento humano, não sendo exclusivo para os cientistas da computação, sendo uma habilidade fundamental a todas as áreas, inclusive é manifestado na idade infantil, quando a criança utiliza sua habilidade analítica de selecionar procedimentos para resolução de problemas.

O pensamento computacional representa uma computação desplugada, que não necessita única e exclusivamente do computador para acontecer, mas que pode ser percebida em ações e atividades voltadas ao pensar e ao agir. Para Ramos (2014, p. 27), "as ferramentas da computação ampliam nossa capacidade mental, uma vez que traduzem nossas abstrações e intenções em solução de problemas com o uso de modelos computacionais". Tal situação é perceptível quando se usa softwares e busca-se nas estruturas mentais maneiras de resolver determinadas situações com auxílio do computador - como é o caso do uso do ScratchJr.

Desenvolver o pensamento computacional implica, assim, uma atitude de pensar sobre a ação. Dessa forma, pode-se reconhecê-lo como um processo constante de desequilíbrios e aprimoramento dos esquemas do sujeito, já que permite um trabalho ativo sobre o próprio sistema cognitivo. Nessa direção, diversas iniciativas permitem explorar o potencial da programação de computadores para o desenvolvimento cognitivo das crianças, dentre as quais destacamos o Projeto Berçário de Hackers, inserido no Programa Mutirão pela Inclusão Digital.

\section{O PROGRAMA MUTIRÃO PELA INCLUSÃO DIGITAL E O PROJETO BERÇÁRIO DE HACKERS}

O Programa Mutirão pela Inclusão Digital surgiu em 2004, vinculado ao Grupo de Pesquisa em Cultura Digital (GEPID) da Universidade de Passo Fundo (UPF), de Passo Fundo, município da região norte do estado do Rio Grande do Sul. Desde sua origem, o Programa tem como objetivo implementar ações que possibilitem o início de um processo de apropriação das tecnologias de 
rede, por meio de informática educativa, além de articular as ações para a criação de oportunidades de desenvolvimento de competências cognitivas por estudantes da educação básica através da programação de computadores e robótica educativa.

O Projeto Berçário de Hackers, por sua vez, está inserido no referido programa e destina-se a crianças de escolas de educação infantil da rede municipal de Passo Fundo. Tem como objetivo incentivar a programação de computadores em tais estudantes, como forma de promover a construção colaborativa e criativa em interação com os colegas, de maneira a estruturar as aprendizagens. As oficinas do Projeto tiveram início em 2013, com atividades diversas envolvendo tecnologias digitais, com crianças de quatro a seis anos. No ano de 2014, a proposta foi redimensionada, de modo a ser trabalhada especificamente a programação de computadores, por meio do site Code.org, que explora blocos de programar. Ao final de 2014, quando o ScratchJr chegou ao Brasil, o planejamento do projeto foi redirecionado para o trabalho com o esse novo software.

Assim aconteceu e, em 2015, foram desenvolvidas atividades de lateralidade, manuseio nos tablets e sequenciamentos didáticos que visavam ao desenvolvimento do raciocínio lógico, conhecimento dos números e do alfabeto. Foi nesse ano que se implementou a metodologia de três ambientes distintos com intencionalidades comuns. Com tais dinâmicas, já foram atendidas mais de 160 crianças desde o ano de 2013 e, no ano de 2016, o projeto contou com a presença de uma turma de 19 crianças de pré-escolar, com idades de cinco e seis anos, acompanhadas pela professora titular. As oficinas tiveram periodicidade semanal, com duração de 90 minutos, e o planejamento realizou-se conforme o ritmo da turma, sendo que os monitores se reuniam quinzenalmente e contemplavam as necessidades/ especificidades da turma para poder inserir o software ScratchJr. As atividades aconteceram em três ambientes.

O primeiro deles, denominado SalaLog, envolvia atividades com conceitos matemáticos, como número, quantidade e sequenciamento, além de brincadeiras de lateralidade e movimento do corpo. Foram utilizados blocos lógicos, quebra-cabeças, jogos matemáticos, blocos de programação do software ScratchJr, dentre ou- tros. Também foram desenvolvidos materiais didáticos, que agora estão disponíveis no acervo do Projeto, tais como: jogo de seriação e ordenação, quantificação, lateralidade, comandos do ScratchJr produzidos em impressora 3D pelos monitores do curso de Ciência da Computação, além do jogo de blocos lógicos.

No segundo ambiente, chamado SalaTec, as atividades aconteceram com os tablets, sobre os quais foram aplicados alguns conceitos aprendidos na SalaLog e, posteriormente, a programação do software ScratchJr. Por fim, após manusearem os tablets, as crianças foram direcionadas para o terceiro espaço, denominado LabComp, onde tinham a prerrogativa de escolher jogos de seu interesse. Isso, porém, sempre com a orientação e acompanhamento dos monitores, os quais observavam as potencialidades e habilidades das crianças com os computadores e o seu grau de autonomia. O caráter ainda iniciante desse Projeto para a realidade da educação infantil impele à busca da compreensão de como se dá o desenvolvimento cognitivo das crianças que participam do Berçário de Hackers. Motivo pelo qual apresenta-se o percurso metodológico adotado para este estudo que se deu, retomando-se, com o objetivo de identificar a relação entre o conceito de equilibração majorante e as atividades de programação de computadores realizadas por crianças da educação infantil participantes do Projeto Berçário de Hackers.

\section{PERCURSO METODOLÓGICO}

Este estudo caracterizou-se como qualitativo e teve sua abordagem metodológica pautada na pesquisa-ação. O pesquisador, no contexto da pesquisa qualitativa, debruça-se sobre aquilo que $o$ campo lhe mostra e, fortemente amparado na teoria, dá significado às ações dos sujeitos observados. Seu papel, segundo Lüdke e André (2015, p. 5), “é justamente o de servir como veículo inteligente e ativo entre esse conhecimento construído na área e as novas evidências que serão estabelecidas a partir da pesquisa". Fazer avançar o conhecimento exige rigorosidade do pesquisador, que deve colocar-se de maneira ética no campo e respeitar a perspectiva apresentada pelos participantes da pesquisa. 
Para os contornos da pesquisa qualitativa, a pesquisa-ação mostrou-se ideal por caracterizar-se pela resolução de algum problema, ou mesmo uma ação, em que os pesquisadores se envolvem de forma cooperativa, tendo uma postura de escuta e não uma imposição com interesses apenas unilaterais. Thiollent (1988, p. 16) afirma que "não se trata de simples levantamento de dados ou de relatórios a serem arquivados. Com a pesquisa-ação, os pesquisadores pretendem desempenhar um papel ativo na própria realidade dos fatos observados".

Os procedimentos técnicos adotados para a produção de dados primários constituíram-se da observação participante e de vídeogravações nas oficinas do Projeto Berçário de Hackers, nos ambientes SalaTec e SalaLog e na tela do software
ScratchJr. A partir de tais instrumentos produziu-se a transcrição de algumas cenas, intencionalmente selecionadas, de maneira a nortear a posterior análise dos dados. Participaram da pesquisa 19 crianças de cinco e seis anos da Escola Municipal de Educação Infantil Cantinho Feliz, turma de Pré II, localizada na Rua Telmo Ilha, s/n, no Loteamento Leonardo Ilha, próximo à UPF. Essas eram acompanhadas pela professora titular, uma vez por semana, até a Universidade, para participarem das oficinas do Projeto, entre os meses de abril e novembro de 2016. Dessa amostra de sujeitos foram selecionados dois estudantes para uma análise mais detida, pelo critério de assiduidade nas oficinas e pela especificidade de suas interações no Projeto, nomeando-os E11 e E18, como se vê no Quadro 1.

Quadro 1 - Estudantes que que compõem o grupo-sujeito para a análise de dados.

\begin{tabular}{|c|c|c|l|}
\hline Identificação & \multicolumn{1}{|c|}{ Idade } & Gênero & \multicolumn{1}{c|}{ Características do estudante } \\
\hline E11 & 5 anos e 5 meses & Masculino & $\begin{array}{l}\text { E11 destacou-se pelo raciocínio lógico ágil. Não } \\
\text { era um dos estudantes que mais falava, porém } \\
\text { era atento à proposta e a executava rapidamente. } \\
\text { Demonstrava alegria em participar dos diferentes } \\
\text { espaços e, mesmo sendo um dos mais novos da } \\
\text { turma, não teve grandes dificuldades em manu- } \\
\text { sear a tecnologia. }\end{array}$ \\
\hline E18 & 5 anos e 4 meses & Masculino & $\begin{array}{l}\text { E18 era um menino que demonstrava dificuldade } \\
\text { em concentrar-se nas propostas, bem como no } \\
\text { entendimento das atividades. Ao tempo em que } \\
\text { os demais estavam realizando-as, em muitos } \\
\text { momentos mantinha-se brincando, pedindo para } \\
\text { ir ao banheiro ou simplesmente não realizando } \\
\text { o que havia sido proposto. }\end{array}$ \\
\hline
\end{tabular}

Fonte: Elaborado pelos autores deste artigo.

Definidos os contornos da pesquisa e a amostra de sujeitos, elegeu-se três categorias de análise, nascidas do aporte teórico sobre equilibração majorante, sendo elas: ampliação dos esquemas do sujeito, construção gradativa de negações e ação do sujeito. Situações ocorridas em duas oficinas foram selecionadas para análise, correspondentes aos dias 02 de maio de 2016 e 24 de agosto de 2016 .

A primeira oficina selecionada, intitulada Jogo de Lateralidade, teve o objetivo de verificar como as crianças veem a lateralidade e despertar o entendimento das direções. Para a execução da atividade utilizou-se trilhas e setas de direção colocadas no chão da sala, da mesma maneira que as crianças encontrariam no computador. Iniciou-se a oficina do dia com a turma toda na SalaLog. Em um primeiro momento, com as crianças dispostas em círculo, perguntou-se sobre as partes do corpo"onde ficam as orelhas? Onde ficam os joelhos?", e assim por diante. Seguiu-se com outras indagações: 
"Há alguém atrás de você? Qual é a cor do cabelo do colega que está à sua direita? Qual é o nome do colega que está sentado à sua esquerda?".

Colou-se um adesivo na mão direita das crianças e colocou-se a música "Vem que eu vou te ensinar". Após esse momento, mostrou-se as flechas e conversou-se sobre o significado de cada uma. Dispôs-se as trilhas diferentes e chamou-se as crianças em duplas para resolvê-las. Uma criança permanecia em frente à trilha, a outra ficava com as flechas e descobria quais eram as flechas necessárias para aquela trilha. Os colegas ajudavam a pensar para que lado a flecha indicava a partir de perguntas motivadoras como: "Para essa trilha dar certo, quais flechas são necessárias?”. A Figura 3 apresenta o Episódio 1 [Ep1C1], que se passou na SalaLog, com a presença de 16 crianças, destacado para análise.

Figura 3 - Episódio 1, Cena 1 [Ep1C1].

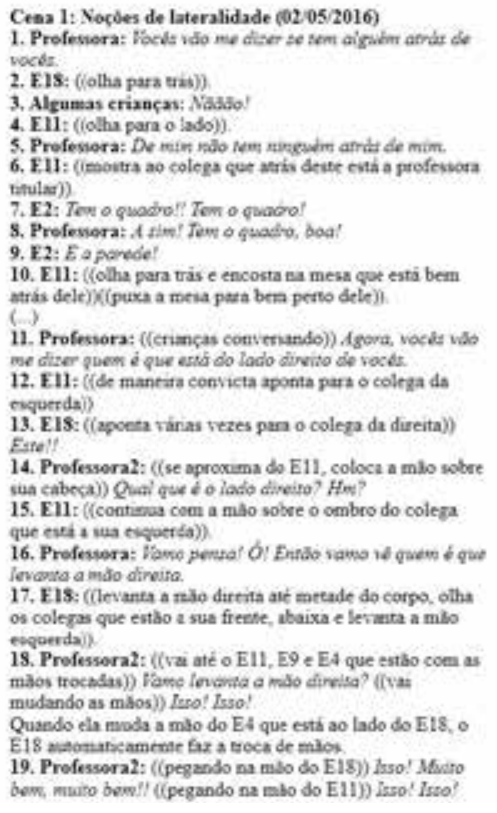

Cesa 1: Nociles de lateralidade (02/05/2016) 1. Profesiera: Kacls vdo me diser se sem aiguim atral of

4. E11: (iolha para o iado) )

10. E11: (Colha para tris cencosta ga mess gre esta bet atras

)) Agora, vaces vido

13. E18: ((apoeta várias vezes pan o colega da direita))

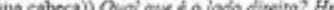

15. Ell: (contisus com a nito sobre o ombro do colen

que extit i ua eicoerta)

leveras a mido dinito.

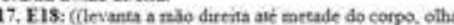

os colegrs que estào a sua frette, ubaixa e levinua a mbo

19. Professora2: (ivai até o E11, E9 e E4 que estáo cona a

Quendo ela moda a mito do E4 que estí ao lado do E18, o

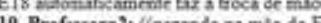

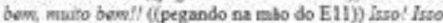

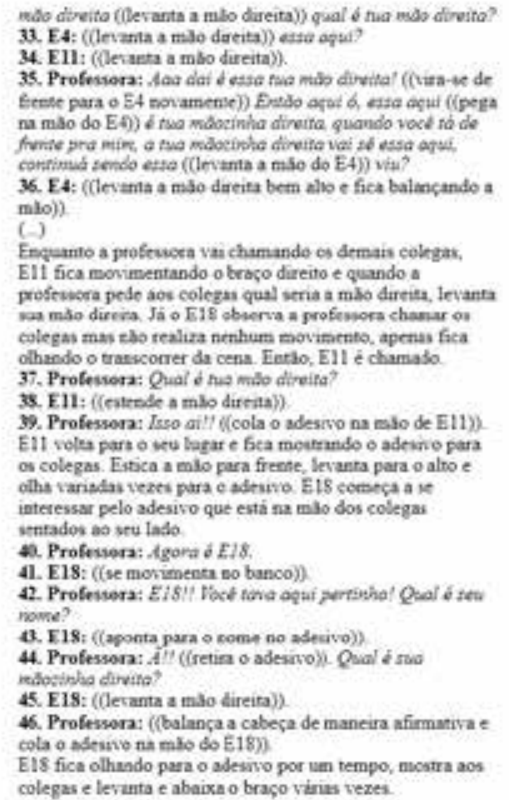

Fonte: Elaborado pelos autores deste artigo.

Na segunda oficina selecionada para este estudo, realizada em 24 de agosto de 2016, objetivou-se mobilizar o entendimento de quantidade, construção de formas geométricas e lateralidade para desenvolver um percurso. Para a execução da atividade, juntou-se mais de uma trilha e assim foi-se aumentando o grau de complexidade e entendimento. Um grupo passou a oficina toda no computador e o outro grupo participou das atividades na SalaTec e na SalaLog.

$\mathrm{Na}$ SalaLog fez-se uma chuva de ideias no quadro para escolher o nome do grupo junto com as crianças. Em seguida, cada criança recebeu um pedaço de sulfite branco para desenhar o seu gatinho, do jeito que desejasse, com as cores e instrumentos que quisesse. Pediu-se que escrevessem os seus nomes dentro do retângulo que estava no papel. Depois, entregou-se um percurso para as crianças e, juntos, pensou-se quais eram os quadradinhos para pintar e fazer o gato desenhar um quadrado. Na SalaTec retomou-se a pintura do gatinho. Depois iniciou-se a execução de alguns comandos de movimento, conforme apresentado na Cena 1 do Episódio 2 [Ep2C1], na Figura 4, que aconteceu na SalaLog, com a participação de 10 crianças. Na sequência, na Figura 5 apresenta-se o Episódio 2, Cena 2 [Ep2C2], que ocorreu na SalaTec com as mesmas crianças da cena anterior, quando estavam sentadas nos bancos, manuseando os tablets. 
Figura 4 - Episódio 2, Cena 1 [Ep2C1].

\begin{tabular}{|c|c|c|c|}
\hline Cesa 1: Athidade com percurno (24:65:2016) & 17, Todos: Graste' Grande' Gonde? & 39. Protestera: Pra cat snde? & 52. EII: (ipentasde para a escuerde) \\
\hline 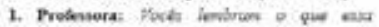 & 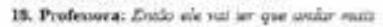 & कs. x11:Mnetimas & 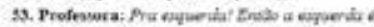 \\
\hline 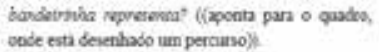 & 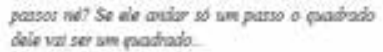 & 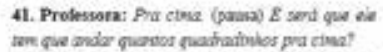 & 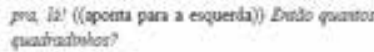 \\
\hline 2. E4: $\dot{A} \geq$ in! & 19. Irodos: Poguencos! & 42. ES E EI1: $1,2,3,4,5$ (countaram o nimeto de & 54. EVI: The!ly \\
\hline 3. Profesiora: $d$ th & 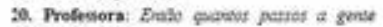 & 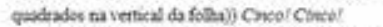 & 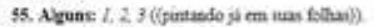 \\
\hline 4. I11: (lesata obrace)) (isadivel) incla?? & podena coibod? & 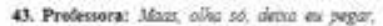 & 56. Pretessora: Pra eqguerda. \\
\hline 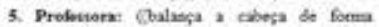 & A. EII: Sont? & 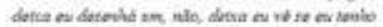 & $\omega$ \\
\hline 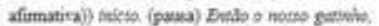 & 22. Profenera: Seit?? & 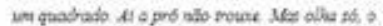 & 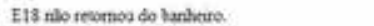 \\
\hline 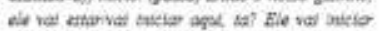 & 23. Es: Ses minces! & 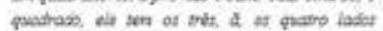 & 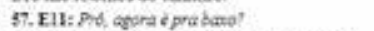 \\
\hline 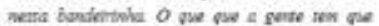 & 24. Alquans Seter Sett' (gntos) tinantivell. & 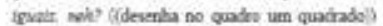 & 1s. Prefessorat (Cesti atendeodo cutra criaçak. \\
\hline fere gra que ease garnho faga it ande on an & 2S. Profesiora: $S \delta$ pae, so que tow so pondw & 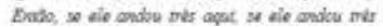 & 99. ril: Pro arova i pra bavo' Pra baceet \\
\hline 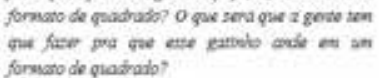 & 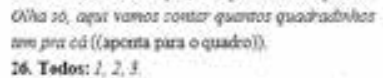 & 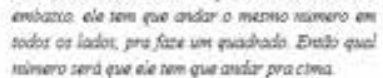 & 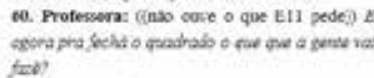 \\
\hline 6. E11: (levesa otrayo)). & 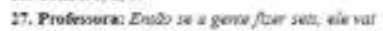 & 4. 111 The? & A. Alguas Pra baasae? \\
\hline 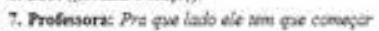 & ath ford & 45. Es: Csace? & 2. Profesiora: Pha batus Quantos gra bated? \\
\hline a osdorterd? & 3. E.11: Jat'l & 4S. E11: TWh & a. Alzune Jhe'! \\
\hline 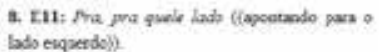 & 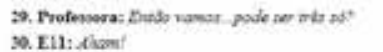 & 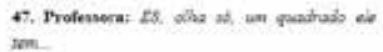 & 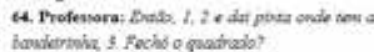 \\
\hline 9. Professora: Ta, names consepay (inasive). & 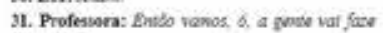 & 45. $211:$ \& sk! & 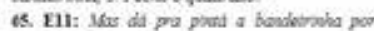 \\
\hline 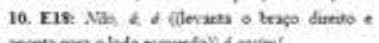 & cie ande 2 . & 40. Prokestora: st prathe iadog ignurt. Endo se & dentre datis? \\
\hline upenta para o lado soquerdo) 6 antint & 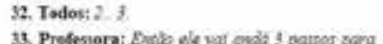 & 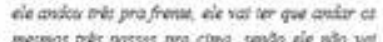 & 66. Professors: Podie \\
\hline 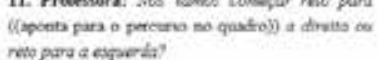 & $\begin{array}{l}\text { call } \\
\text { 3. Aiguas teits }\end{array}$ & 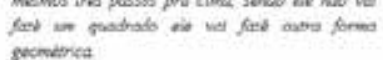 & E18 ands nbo resconose do buthrevo e E11 to \\
\hline 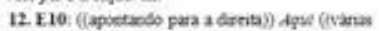 & (.) & (n) & 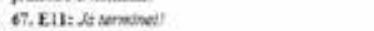 \\
\hline crianças falum 20 neums verpo), (inaodivel! & 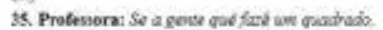 & EIt peciu para ir as boeheizo, poren, ia tinhu & 6s. Prefessora: leso at? \\
\hline 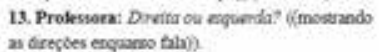 & 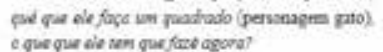 & 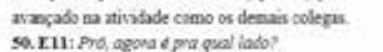 & 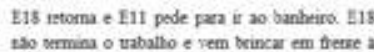 \\
\hline 14. Todat: Donevezalf & 36. Es: I reto grat ed: & 51. Probusora: (Cotha para EII cae je faz o sinal & cimera. \\
\hline 15. Es: Diveta d para o ladio & 57. E1s: fiothado para on lados e trincrodo com & pan a equesda)) asso oft igora se a gerte gid & \\
\hline 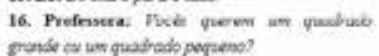 & 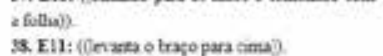 & 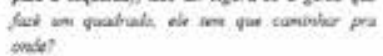 & \\
\hline
\end{tabular}

Fonte: Elaborado pelos autores deste artigo.

Figura 5 - Episódio 2, Cena 2 [Ep2C2].

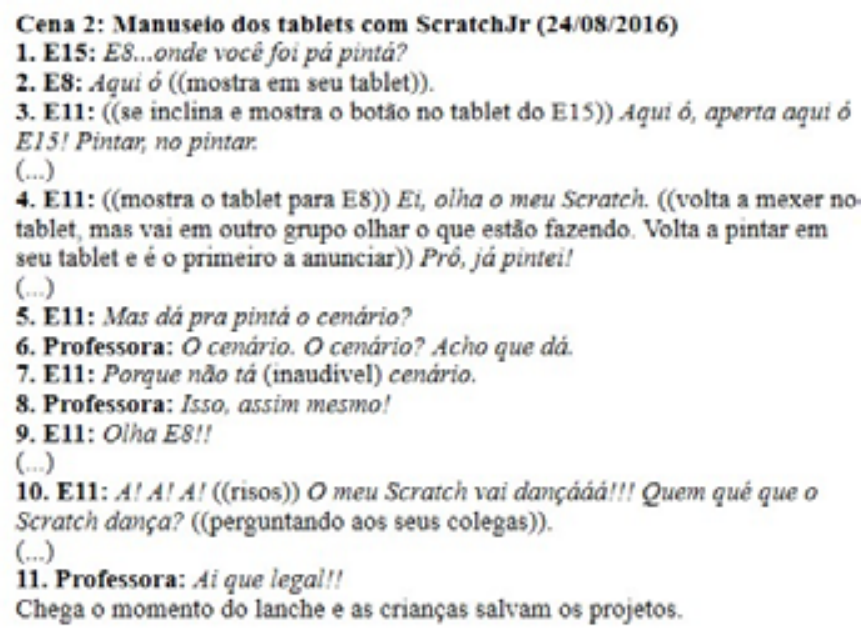

Fonte: Elaborado pelos autores deste artigo.

A partir do planejamento e da transcrição desses dois episódios, mapeou-se as manifestações das categorias a fim de compreender, na direção do objetivo precípuo deste estudo, como se manifestam os processos de regulações ativas e automáticas das crianças de cinco e seis anos, tendo em vista a identificação de evidências de equilibrações majorantes, mediante a ação em atividades de programação de computadores realizadas no âmbito do Projeto Berçário de Hackers. Esse movimento permitiu resultados e evidências que são descritos na sequência. 


\section{APRESENTAÇÃO E DISCUSSÃO DOS DADOS}

A primeira categoria de análise vislumbrada - a ampliação dos esquemas do sujeito - diz respeito à capacidade dos sujeitos de desenvolverem esquemas cada vez mais aperfeiçoados. Isso se dá através da assimilação de fatores externos a estruturas internas. Tais fatores desestabilizam o sujeito, causando desequilíbrio inicial, porém, a partir do momento que esse opta por uma regulação ativa, ou seja, encara o desequilíbrio, acontece o princípio da transformação e, dessa maneira, da ampliação do sistema cognitivo do sujeito. Revisitando os episódios, é possível encontrar indícios de ampliação dos esquemas em E11.

No Ep1C1 essa ampliação pode ser visualizada quando da interação da professora com os colegas de E11, havendo a reflexão desse perante sua lateralidade com certa resistência, assim como para a exigência externa. Após várias falas da professora com seus colegas é que E11 começou a movimentar as duas mãos e a olhá-las com certa inquietação. A mudança de perspectiva aconteceu a partir do momento em que começou a levantar o braço direito, demonstrando os pensamentos que começaram a se passar em seu interior. A ampliação do esquema de lateralidade aconteceu nesse instante, muito embora tenham ocorrido outras situações em que a dúvida surgiu novamente, o que faz entender que há dificuldade na estruturação da lateralidade em crianças, exigindo revisitações constantes ao conceito.

Em Ep2C1 acontece outro importante aprimoramento do esquema de E11. Ele ressignifica sua ação para conseguir concluir o percurso proposto. É necessário que o estudante utilize dois subsistemas em conjunto, direção e numeração, e o que se percebe é que não há tal reciprocidade no momento da ação, mas os subsistemas encontram-se em velocidades distintas. Quando E11 toma consciência de que é necessário cuidar de fatores distintos ao mesmo tempo, acontece a compensação e a consequente ampliação do esquema. O processo de equilibração majorante é intenso nessa cena, sendo possível visualizar as etapas de desequilíbrio, regulação automática e posterior regulação ativa, completada com a ação do sujeito.
Na segunda categoria de análise - construção gradativa de negações - é reconhecida a importância das negações, enquanto carências iniciais e constituintes de importantes enriquecimentos do sistema cognitivo.

A construção de negações vem com a valoração das regulações automáticas, sendo que o sujeito elimina a perturbação que o desequilibrou e a mantém em estabilidade, reforçando seu próprio esquema em comparação ao necessário para superar o desequilíbrio. Embora mantenha o indivíduo em estabilidade, esse é, para Piaget (1976), o enriquecimento imprescindível em todo o processo, pois transforma a carência em posterior equilíbrio, fazendo com que o sujeito pense sobre seus esquemas e sistema cognitivo.

Entre as cenas, mapeou-se alguns momentos em que E11 e E18 vivenciaram suas negações ou regulações automáticas. No Ep2C1 é clara a construção de negações por E11, que cria sua hipótese acerca do percurso que irá desenvolver. Ao observar tal percurso, juntamente com a professora, ele entende que não pode ultrapassar os quadrados disponíveis, constatando a necessidade do esquema para a numeração. Algo que ele não se dá conta é que ao tempo em que precisava cuidar da numeração, deveria considerar também a forma que o percurso iria ter. Acontece, assim, um feedback positivo no momento em que reforça seus esquemas de pensamento, não dando conta do formato quadrado que precisava constituir. Entretanto, até mesmo essa regulação automática foi importante para a posterior ampliação do esquema que aconteceu, sendo que E11 evidencia ter passado por todos os complexos ciclos da equilibração majorante.

Em E18, no Ep1C1 pode-se visualizar o caso de estabilidade. Isso porque todas as manifestações que realizou correspondiam aos questionamentos feitos pela professora. Embora nas semanas seguintes tenha apresentado dificuldades em sua lateralidade, nessa cena aconteceu o reforço de algum estímulo já vivenciado. Não se caracterizou como a construção de negações, pois não houve ação impactante do sujeito quanto à negação, mas reforçou algo que estava apropriado de forma adequada, sendo definida como uma regulação automática e consequente estabilidade. 
Por fim, na terceira categoria de análise - ação do sujeito - deposita-se a centralidade da obra de Piaget. Através das ações do sujeito é que acontecem as construções de novos conhecimentos ou a opção pela estabilidade. Essa última categoria traz consigo algumas reflexões importantes sobre as transcrições revisitadas, sendo a presença de E11 nas cenas constante e de grande protagonismo, papel que não fica tão claro em E18.

No Ep2C2 visualiza-se a ação de E11 ao manusear o software e descobrir através dele novos caminhos para sua aprendizagem. Assim como é uma conquista para ele, ao interagir, compartilha esse êxito com os colegas igualmente. No momento em que age sobre suas dúvidas e incertezas, promove a construção de novos saberes, e o avanço em seu sistema cognitivo. Nota-se nos indícios de ação de E18 que sua postura acontecia de forma mais introspectiva, sem evidenciar claramente como mobiliza ações que incidem sobre sua aprendizagem.

A partir das análises realizadas, perscrutou-se evidências dos processos acontecidos durante as oficinas na aprendizagem dos dois estudantes, nomeadamente E11 e E18. Tais processos ocorreram de maneiras distintas, tendo em vista o fato de que cada criança possui suas individualidades. Constatou-se, assim, que não existe ampliação dos esquemas do sujeito sem a ação desse e sem a negação dos desequilíbrios. E11 vivenciou intensamente vários processos da equilibração majorante no decorrer das cenas transcritas, e ao viver os variados processos é que dá indícios de desenvolvimento de seu sistema cognitivo de maneira mais complexa. Nas condutas de E18 verifica-se um descompasso entre as categorias, o que leva a se reiterar as premissas construtivistas acerca do protagonismo dos estudantes como elemento que impulsiona as ampliações do próprio sistema cognitivo.

Por meio da ação o sujeito direciona e encaminha as situações que acontecem em sua vida, permitindo questionar-se, criar hipóteses, ter dúvidas e buscar respostas, ou não respostas. Mesmo quando decide manter-se em estabilidade, faz escolhas conscientes sobre seu aprender. E18 não agiu em torno do objeto em alguns momentos, havendo cenas em que até mesmo manteve-se fora da oficina. Talvez, se sua participação tivesse sido mais frequente, os processos envolvidos seriam intensificados e produziriam ampliações mais significativas de seus esquemas.

Ao finalizar essa apreciação dos dados, sinaliza-se que duas crianças viveram as mesmas experiências, porém cada uma agiu de maneira diferente sobre aquilo que experimentou. E11 agiu sobre vários momentos de sua aprendizagem e adentrou a proposta das oficinas, demonstrando ocasiões variadas de regulações ativas e automáticas, sendo que, por vezes, essas confundiram-se e impulsionaram uma à outra. Por meio de negações das imposições externas, aceitação e ressignificação dos próprios esquemas e protagonismo para com seu aprender e dos colegas, E11 vivenciou intensos desequilíbrios e reequilibrações, havendo diversos indícios de equilibração majorante.

E18, por sua vez, vivenciou o processo das oficinas de maneira mais neutra, porém houve momentos de igual significância, quando a professora o auxiliou a encontrar os caminhos para a superação dos desequilíbrios. A ação ocorreu com menor frequência, e com menor visibilidade aos olhos dos pesquisadores, o que não significa que não tenham ocorrido situações de ampliações dos esquemas.

\section{CONSIDERAÇÕES FINAIS}

O primeiro grande entendimento proporcionado por este estudo é a clareza de que a programação de computadores é composta por diferentes momentos e não se dá exclusivamente no espaço e tempo onde o software é utilizado, sendo essa tão somente a ocasião de representação de habilidades e de sistematização. É preciso que as crianças tenham contato com um universo de sensações e experiências, especialmente aquelas referentes à computação desplugada, para posteriormente viverem a execução de suas programações.

A partir das categorias de análise foi possível ampliar a visão e perceber que durante o processo de programação de computadores manifestaram-se diversos indícios de regulações ativas e automáticas em ambos os estudantes. Essas últimas envolveram inúmeras negações dos desequilíbrios ocasionados pelas atividades desenvolvidas. Desde o momento em que houve negação e o sistema se manteve em estabilidade, até o momento de aceitação e opção pela mudança, percebeu-se que houve um expressi- 
vo crescimento cognitivo entre os sujeitos, mesmo que em alguns momentos não compreendessem o processo que acontecia dentro deles. Isso porque as regulações automáticas proporcionaram uma negação momentânea que foi superada e melhorada, exercendo, então, imprescindível papel nas futuras equilibrações.

As ações realizadas pelos estudantes acabam trazendo implicações em seu próprio desenvolvimento, uma vez que a presença de E11 nas cenas é constante, mas a ação de E18 não fica tão clara. Essa constatação faz perceber que E11 avançou mais, do ponto de vista cognitivo, do que E18, isso porque resolveu-se com suas dúvidas de maneira mais autônoma, fato visível no decorrer de todo o ano de oficinas. A ação de cada estudante foi importante para os processos vivenciados, logo, esses ocorreram de maneiras diferentes devido ao fato de que cada criança possui suas individualidades.

Contempla-se, ainda, que grande parte das ampliações dos esquemas de cada um dos estudantes foi possível pelos processamentos internos acontecidos, em intensa e complexa interação com a professora, com os pares, com o software de programação e com os objetos de conhecimento. Todavia, ainda que seja imprescindível a presença desses elementos, é fundamental que as crianças tomem consciência de todo esse percurso para que o engrandecimento do sistema cognitivo encontre abrigo.

Ao finalizar o estudo, compreende-se que por meio dele efetivou-se um importante passo em direção ao conhecimento do potencial da programação de computadores para um público ainda a ser amplamente observado - as crianças da educação infantil. Mais do que isso, desenvolver uma pesquisa sobre as potencialidades das tecnologias para a aprendizagem no universo da infância, envolvendo especificamente crianças de cinco e seis anos de idade, simboliza o compromisso com esse nível de escolarização, que está, apenas recentemente, se consolidando no âmbito das políticas públicas.

Reitera-se aqui a ideia de que muitas das crianças que acedem à escola atualmente participam, em alguma medida, de um mundo digitalizado e trazem consigo demandas que são específicas desse cenário. Portanto, os processos de ensino-aprendizagem capitaneados pela escola não podem furtar-se de levar em conta as tecnologias já utilizadas por elas e também de oferecer-lhes outras possibilidades que, porventura, ainda não façam parte do seu universo, como é o caso da programação de computadores.

\section{REFERÊNCIAS}

BECKER, F. Educação e construção do conhecimento. Porto Alegre: Artmed, 2001.

BONILLA, M. H. S. Escola aprendente: para além da sociedade da informação. Rio de Janeiro: Quartet, 2005.

BRASIL. Constituição da República Federativa do Brasil: Constituição de 1988. Brasília, DF: Senado Federal, 1988.

Ministério da Educação. Secretaria de Educação Básica. Diretrizes curriculares nacionais para a educação infantil. Brasília, DF: MEC, 2010. Disponível em: <https://goo.gl/pEjiHV>. Acesso em: 22 fev. 2017.

. Ministério da Educação. Secretaria de Educação Básica. Base nacional comum curricular. 3. ed. Brasília, DF: MEC, 2017. Disponível em: <https://goo.gl/P5e5PG>. Acesso em: 21 set. 2017.

BRUNER, J. A cultura da educação. Porto Alegre: Artmed, 2001.

GOMES, E. M. Desenvolvimento de atividades pedagógicas para a educação infantil com a lousa digital interativa: uma inovação didática. 2010. 169 f. Dissertação (Mestrado em Educação) - Universidade Estadual de Campinas (Unicamp), Campinas, SP, 2010. Disponível em: <https://goo.gl/w7Lijw>. Acesso em: 15 jul. 2016.

LIMA, E. S. Neurociência e aprendizagem. São Paulo: Inter Alia Comunicação e Cultura, 2007.

LÜDKE, M.; ANDRÉ, M. E. D. A. Pesquisa em educação: abordagens qualitativas. 2. ed. Rio de Janeiro: E.P.U., 2015.

MACHADO, M. R. Percepção de profissionais da educação infantil: a interação de crianças com um artefato tecnológico. 2011. 117 f. Dissertação (Mestrado em Tecnologia) - Universidade Tecnológica Federal do Paraná, 
Curitiba, 2011. Disponível em: <https://goo.gl/UgXz9f>. Acesso em: 15 jul. 2016.

MONTANGERO, J.; MAURICE-NAVILLE, D. Piaget ou a inteligência em evolução. Trad. Fernando Becker e Tânia Beatriz Iwaszko Marques. Porto Alegre: Artmed, 1998.

PAPERT, S. A máquina das crianças: repensando a escola na era da informática. Porto Alegre: Artes Médicas, 1994.

PIAGET, J. A equilibração das estruturas cognitivas: problema central do desenvolvimento. Trad. Marion Merlone dos Santos Penna. Rio de Janeiro: Zahar, 1976.

QUEIROZ, N. A “nova matemática”. Correio Braziliense, Brasília, p. 14, 12 mar. 2012. Disponível em: <https:// goo.gl/Z8LMGT>. Acesso em: 10 jun. 2016.

RAMOS, H. A. Pensamento computacional na educação básica: uma proposta de aplicação pedagógica para alunos do quinto ano do ensino fundamental do distrito federal. 2014. 119 f. Monografia (Graduação em Computação) - Universidade de Brasília (UnB), Brasília, DF, 2014. Disponível em: <https://goo.gl/WzgJAX>. Acesso em: 15 jul. 2016.

ROCHA, A. N. D. C. Processo de prescrição e confecção de recursos de tecnologia assistiva para educação infantil. 2010. 201 f. Dissertação (Mestrado em Educação) - Universidade Estadual Paulista (Unesp), Marília, SP, 2010. Disponível em: <https://goo.gl/s6wNqt>. Acesso em: 15 jul. 2016.

SANTOS, J. A. Computador: a máquina do conhecimento na escola. 2007. 162 f. Dissertação (Mestrado em Educação) - Universidade de São Paulo (USP), São Paulo, 2007. Disponível em: <https://goo.gl/k7c6Kv>. Acesso em: 15 jul. 2016.

SCRATCHJr. Guia de interface. Disponível em: $<$ https://www.scratchjr.org/learn.html>. Acesso em: 15 jul. 2016.

SILVA, C. A. Crianças e computadores: um estudo exploratório sobre a informática na educação infantil no Distrito Federal. 2010. 112 f. Dissertação (Mestrado em Educação) - Universidade de Brasília (UnB), Brasília, DF, 2010. Disponível em: <https://goo.gl/LYMKuu>. Acesso em: 15 jul. 2016.

THIOLlENT, M. Metodologia da pesquisa-ação. São Paulo: Cortez, 1988.

VEEN, W.; VRAKKING, B. Homo zappiens: educando na era digital. Porto Alegre: Artmed, 2009.

Recebido em: 15/12/2018

Aprovado em: 01/10/2018 